\title{
Towards Circular Economy implementation: an agent-based simulation approach for business model changes
}

\author{
Michael Lieder ${ }^{1}$ (D) - Farazee M. A. Asif ${ }^{1}$. \\ Amir Rashid ${ }^{1}$
}

Published online: 9 May 2017

(C) The Author(s) 2017. This article is an open access publication

\begin{abstract}
This paper introduces an agent-based approach to study customer behavior in terms of their acceptance of new business models in Circular Economy (CE) context. In a CE customers are perceived as integral part of the business and therefore customer acceptance of new business models becomes crucial as it determines the successful implementation of CE. However, tools or methods are missing to capture customer behavior to assess how customers will react if an organization introduces a new business model such as leasing or functional sales. The purpose of this research is to bring forward a quantitative analysis tool for identifying proper marketing and pricing strategies to obtain best fit demand behavior for the chosen new business model. This tool will support decision makers in determining the impact of introducing new (circular) business models. The model has been developed using an agent-based modeling approach which delivers results based on socio-demographic factors of a population and customers' relative preferences of product attributes price, environmental friendliness and service-orientation. The implementation of the model has been tested using the practical business example of a washing machine. This research presents the first agent-based tool that can assess customer behavior and determine whether introduction of new business models will be accepted or not and how customer acceptance can be influenced to accelerate $\mathrm{CE}$ implementation. The tool integrates socio-demographic factors, product utility functions, social network structures and inter-agent communication in order to comprehensively describe behavior on individual customer level. In addition to the tool
\end{abstract}

Electronic supplementary material The online version of this article (doi:10.1007/s10458-017-9365-9) contains supplementary material, which is available to authorized users.

Michael Lieder

lieder@kth.se

Farazee M. A. Asif

aasi@kth.se

Amir Rashid

amirr@kth.se

1 Department of Production Engineering, KTH Royal Institute of Technology, Brinellvägen 68, 10044 Stockholm, Sweden 
itself the results of this research indicates the need for systematic marketing strategies which emphasize $\mathrm{CE}$ value propositions in order to accelerate customer acceptance and shorten the transition time from linear to circular. Agent-based models are emphasized as highly capable to fill the gap between diffusion-based penetration of information and resulting behavior in the form of purchase decisions.

\section{Introduction}

Since 2013 the Circular Economy (CE) movement towards "an industrial economy that is restorative or regenerative by intention and design" [1] has gained a lot of attention in industry. To the largest extent $\mathrm{CE}$ research has been carried out from the perspectives of waste generation, resource use and environmental impact while leaving business and economic perspectives aside [2]. In industrial practice a transition from a linear (take-make-dispose) to a circular product system (considering reuse/remanufacturing/recycling) requires the change of value propositions. In doing so the focus of the value proposition switches from selling a physical product to providing access to functionality through business innovation. As a consequence, $\mathrm{CE}$ business transitions bring manufacturing companies to an uncertain situation since the effects of business model changes are unknown. This scenario also poses the risk of inhibiting CE implementation as advantages for industry are not explicit.

From a socio-technical system perspective, a social network of actors and a physical network of technical artefacts together can form a complex adaptive system [3]. In the CE context described above industrial businesses form such a complex adaptive system between customers (actors) and manufacturing systems (technical artefacts) producing products. Thus, a multi-customer network determines the development, operation and management of the manufacturing system, which in turn affects the behavior of its customers. The CE-view increases the level of complexity in the system, because CE expands the perspective beyond the prevailing linear manufacturing systems in order to gain control about product returns. Since a fundamental assumption at the basis of the presented work is that customers in a CE are perceived as integral part of the manufacturing enterprise a reduction of complexity in socio-technical systems is pursued using simulation of customer behavior.

Using washing machines as example, service-oriented offers which provide access to functionality instead of product ownership have been examined in addition to conventional sales offers. In such a business model the return of the washing machine is determined by the chosen business rationale, i.e. leasing, pay-per-use or other, which in turn is dependent on market acceptance and behavioral aspects of the customers. As a result, the linkage between technical systems (e.g. manufacturing systems) and social systems (e.g. customer networks) becomes enormously significant and influential. It is a manufacturer's objective to fully understand this linkage, particularly in how to handle the consequence and impact of business innovation in the form of new value propositions. An increased understanding in this area would enable manufacturers to gain control over the back end of the market, i.e. quality, quantity and timing of product returns which is considered as one of the critical barriers of CE implementation [4]. Furthermore, moving towards an industrially driven CE consists of simultaneous consideration of business models, product design, supply chain design and technology [5]. In this integrative approach business models are particularly important as they influence product design and supply chain design to maintain profitability. To date tools are missing which can support manufacturing businesses to increase understanding regarding consequences of CE business model transitions. 
In the provided context, the objective of this research is to bring forward an agent-based simulation tool to assist the CE paradigm and enable assessments of customer behavior as a consequence of business model changes. The elements upon which this tool has been based on are: 1) agent-based model (ABM) development describing purchase-decision processes on individual customer level, 2) introduction of new business models using a washing machine case, 3) computer simulation to show the effects of business model changes.

The applicability of the tool is demonstrated through an illustrative case scenario using the ASKO Classic washing machine from Gorenje. The case focuses on the introduction of a buy-back and pay-per-use offer for a washing machine in the Stockholm city area where washing machines are currently sold in a conventional manner. Additionally, a competitive offer is considered in the market scenario. The resulting ABM is supposed to provide insights on customer acceptance and therewith facilitate decision-making for industrial organizations shifting from conventional product sales to service-oriented offers.

In its core this paper addresses a diffusion process and its consequence on customer behavior. A diffusion process has been defined as "speed and degree with which new products, practices and ideas propagate through a society" [6]. As a secondary purpose, the output of this model creates demand streams based on new offerings which serves as input to another model focusing on supply chain scenarios in CE context and which has been carried out in parallel to the work presented in this paper [7]. The remainder of this paper is structured as follows:

Section 2: Review of main principles at basis of this work

Section 3: Concept for modeling individual customer behavior

Section 4: Introduction and formulation of the ABM

Section 5: Description of the case scenario using the example of a washing machine

Section 6: Presentation and discussion of the simulation results

Section 7: Conclusions and research outlook

\section{Background and related work}

This section provides a short justification for the use of an ABM approach and discusses the most relevant existing models to highlight important features as basis for the forthcoming development.

The capabilities of ABMs to capture complex connections between individual customer behavior and overall social dynamics has gained increasing acceptance. This is particularly the case for marketing research where theories of behavior on individual level can be explored [8]. In this perspective, ABMs have been developed to describe diffusion and adoption of innovation.

Typically, customers are represented as agents that are embedded in a social network and thus capable of influencing each other's perception about products or product attributes. Furthermore, depending on the agent's experience during use or inter-agent communication perception about products evolve which leads to changes in perception over time. In this context there is a distinct set of features used in the ABM domain when it comes to describing customer behavior in the context of innovation diffusion. These features can roughly be grouped into emergence of social networks, agent evaluation and decision-making logic and information exchange logic as rationale for agent interaction.

Social connections between customer agents are mostly based on at least one sociodemographic factor, e.g. geographic distance, income, age, etc. Most commonly geographic 
distance is used in $\mathrm{ABMs}$ to describe the likelihood of two agents creating a social bond as the logic is relatively simple to implement in agent-based programs. In such a case distance-based networks are implemented by positioning agents with an individual radius in a continuous space. If another agent is randomly positioned within that radius a connection is created and interaction enabled. In this scenario, the number of connections depends on the density of the agent population and range of the individual radius. More sophisticated models have been developed in order to account for a variety of socio-demographic factors simultaneously [9]. The underlying concept is based on the theory of homophily, which predicts that the probability of information exchange between two individuals depends on the similarity of their socio-demographic factors [10]. Furthermore, there seems consensus in research and practice that socio-demographic factors influence personality traits which in turn have an effect on sensitivity towards different product attributes (such as price or quality) and therefore influence purchase decisions $[11,12]$. Hence, socio-demographic factors have been gaining in relevance when it comes to model the influence on emergence of social networks and intrinsic preferences of a customer.

Evaluation and decision-making processes of customers have naturally been of high interest in business and economics for decades [13]. Besides the use of cognitive approaches in ABMs [14-16] customer preferences can be represented by utility functions in order to make desire and preferences measurable and derive estimations about future demand. The underlying assumption is that if preferences can be represented by a utility function then demand can be concluded based on maximization of utility of a product. In this context, utility functions have been used in various ABMs to describe the logic for decision-making processes. Examples include the emergence of preferences [17], price negotiation skills in a seller-buyer relationship [18], diffusion processes with newly introduced biofuel [19], or policy impacts for service in product-based markets [20]. As can be seen, various ABMs have demonstrated beneficial use of utility functions when modeling customer preferences on individual level and for different product attributes.

In order to model information exchange between agents several different aspects have been considered. The diffusion of information on overall population level has traditionally been modeled by the Bass diffusion [21]. Since heterogeneity of individual customers cannot be accounted for when describing information diffusion on overall population level ABMs have emerged which enable customer interaction on individual level, i.e. sending and receiving of information to replicate word-of-mouth activities [22]. This consequently leads to the discussion regarding content and timing of information exchange on individual level and furthermore how agents are affected by obtaining new information. The content of information exchange at any point in time can be separated into objective elements, e.g. facts to replicate awareness about a product or product attribute, and subjective elements describing opinion, i.e. degree of preference or like/dislike. While the former is used to describe the actual spreading of information through a population the latter involves adaptation of behavior based on the information content. On implementation level customer agent adaptation has been considered by defining parameters which quantify the degree to which extend information contents are adapted [12]. Here, features have been used to account for decay of information impact over time [22]. This allows for customer agents to return their original, i.e. intrinsic, values of opinion if interaction with their environment is disabled. This in turn leads to questions of timing of information exchange in social networks. The choices of agents when to communicate have been made dependent on customer experience and satisfaction level. Assumptions used at this point are that negative product experiences are always communicated [23] while positive product experiences are communicated only to a certain extent. In doing so, ABMs are supposed to mimic scientifically proven customer communication habits. 
Based on the examples above it can be concluded that ABMs have been developed with various features and for various practical cases to gain improved understanding about customer behavior. Popular practical cases consist of the adoption of electric vehicles [24,25] or green energy [26,27]. Most importantly, ABMs that investigate the effect of business model changes on customer behavior in the context of CE have not yet been developed. To date the development of ABMs in the area of customer behavior mainly focuses on a single point of sales in linear production scenarios. Moreover, capable features so far have been developed and applied in the ABM domain to study customer behavior. As these features are applied separately in different business contexts a combination and extension towards circular business models would support and facilitate decision-makers in industry on their way to a profitable $\mathrm{CE}$. The following sections extend the presented research by including aspects of circular product attributes whilst considering a comprehensive set of underlying factors to characterize a customer population. In summary, the ABM to be developed requires

- use of several socio-demographic factors as a basis to form social networks and sensitivities to different product attributes,

- application of utility functions in order to measure preferences for product attributes, specifically for price, environmental friendliness and service-orientation,

- consideration of information exchange between agents including adaptation,

- decay of information content after information exchange.

\section{Modeling concept for individual customer behavior}

In order to bring $\mathrm{CE}$ perspective and capabilities of $\mathrm{ABMs}$ together, a conceptualization of purchase decision-making processes of commodities on individual customer level is necessary. A decision-making process in purchase of commodities can be commonly described as a cognitive process of five stages as shown on the left-hand side of Fig. 1 [28]. The illustrated sequence of stages forms the basis for the tool development, which has already been applied in the context of ABMs. The stages consist of:

1) Need recognition, which can be triggered by internal as well as external stimuli

2) Search for information in order to find a solution for the identified need

3) Evaluation of different solutions on the basis of varying product attributes

4) Purchase decision where the actual purchasing transaction takes place

5) Post purchase behavior in which products are compared with expectations resulting in satisfied or unsatisfied customers

In this context, there are three fundamental stimuli affecting purchase decisions:

\section{Internal stimulus}

- Individual preferences as a result of socio-demographic factors, such as income, age, geographical location, education, etc.

\section{External stimulus}

- Interaction with company information such as price or through e.g. advertisement

- Interaction with other customers in an individual social network e.g. through word-ofmouth

In order to account for the three stimuli in the tool the concept is extended as shown on the right-hand side of Fig. 1 by including underlying factors and influences. These underlying 
factors and influences constitute submodels of the ABM, which are modeled and described independently in Sect. 4.6.

Beginning with socio-demographic factors intrinsic preferences are derived which assume correlations between socio-demographic factors and attributes of a product offer. These intrinsic preferences furthermore build the basis to form product utility and individual networks. The former applies the concept of product utility as a measure for expected and actual preference for an offer. The latter is based on the sociological theory of homophily in social networks which predicts that the probability of information exchange between two individuals depends on the similarity of their socio-demographic factors [10].

Communication between customers is defined as information exchange within a network. Communication depends on individual agent connections to other agents as well as its expected and actual perceived product utilities. The structure of the agent network determines how information is spread and transferred to other agents. The comparison of expected and actual product utility leading to (dis)satisfaction is crucial for deciding the type of information which is to be transferred.

In summary, each single customer is passing continuously through all purchase decisionmaking phases (left side in Fig. 1) while learning from purchase experiences and exchanging information with other customers and advertisement over time. All underlying factors and influences have continuous effect on the stimuli which and make the purchase decision-making process highly dynamic and complex. This scope of the investigation requires an $\mathrm{ABM}$ to allow for sufficient modeling depth to grasp the underlying elements.

The ABM focuses on individuals where single agents represent individual customers. This level of modeling is beneficial for three reasons. Firstly, single households are rather the norm in Scandinavia and particularly in Sweden (estimated with roughly 50\%). Hence, the individual scope provides a reasonable representative case. Secondly, all relevant empirical data on individual level is publicly available and can be easily obtained for the Stockholm area. This also means that data obtained from public sources can be used "as is" without remodeling of data sets and potential information losses. Thirdly, it is common

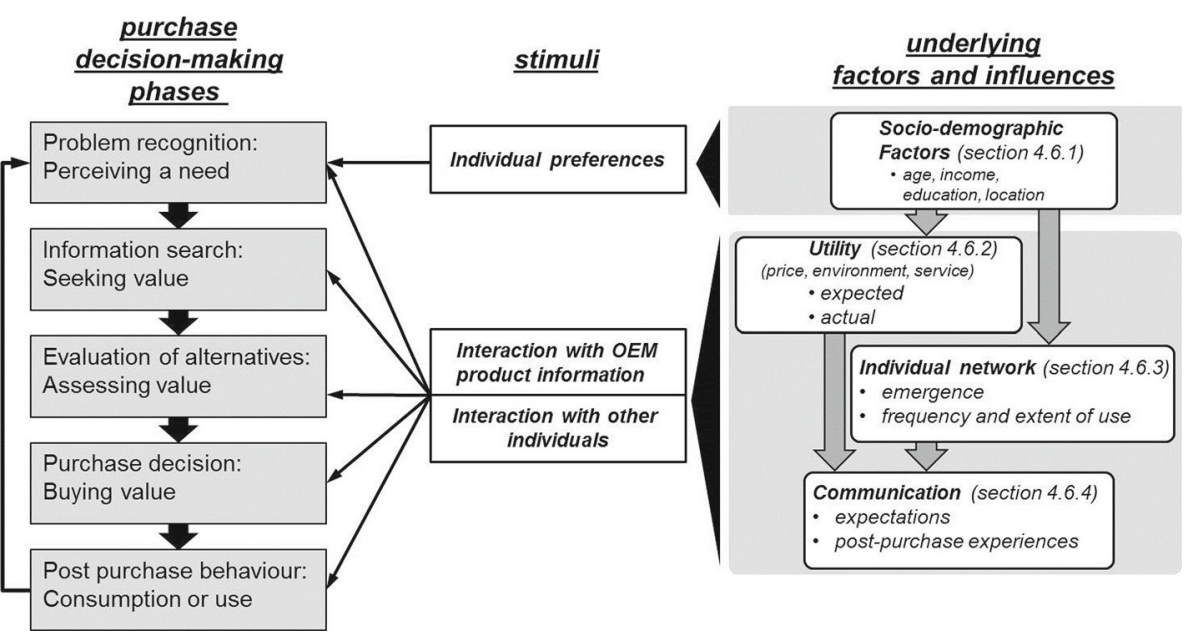

Fig. 1 A schematic customer purchase decision model including three stimuli and underlying factors and influences 
for industry (in this case for the company Gorenje) to relate to socio-demographic factors on individual level (age, income, etc.) rather than e.g. on more aggregated household levels.

In order to ensure alignment with cooperate thinking and to motivate industrial businesses to consider new (circular) business models, the feasibility of buy-back and pay-per-use scenarios is investigated. For the purpose of modeling it is assumed that industrial businesses consider (1) providing access to products rather than ownership and (2) taking their products back for the purpose of value recovery. As a consequence of these two assumptions value propositions to the customers change in the form of new prices (payment for access) and lower environmental impact (refurbishment of product returns as part of a circular business strategy). Furthermore, by moving towards service-oriented offers the level of service provided to customers constitutes a third value proposition (service level agreements). In summary, the product attributes in this work are limited to price, environmental friendliness and service-orientation. The attribute service-orientation implies "convenience" for customers as it is not necessary for the customer to make a comparatively large payment before utilizing the product or to provide storage space for the product after the use phase. On the contrary it is considered that a share of customers might perceive ownership as positive product attribute, thus resulting in an overall rejection of serviceoriented offers such as pay-per-use. The three mentioned product attributes are sufficient for investigating feasible business cases from a company perspective, which has also been discussed and confirmed with the company Gorenje providing the washing machine case in Sect. 5 .

\section{Agent-based model formulation}

The model described in Sect. 3 has been implemented using Anylogic 7.2.0, which is written in Java SE. This section describes the architectural design of the ABM. The model description follows the ODD (Overview, Design, concepts, Details) protocol [29] in order to detail the ABM framework as summarized in the previous section. Supplementary material regarding implementation, tests and calibration can be found in the online resource 1 .

\subsection{Purpose}

Taking washing machines as example, the purpose of this $\mathrm{ABM}$ is to simulate customer behavior with regards to business model changes in CE context. In order to observe changes in demand based on different business models, a customer population is exposed to new offerings of buy-back and pay-per-use of the same product in a competitive market.

\subsection{Entities, state variables and scales}

This ABM includes three types of entities to describe the purchase decision-making process: An environmental agent at population level, individual customer agents and spatial and temporal units. A complete list of all state variables for the properties is provided in the online resource 1 .

The environmental agent contains states and parameters to characterize all customer agents on population level. This includes population size, density and ownership tendency. An information decay factor is included at population level to consider the decay of information after information exchange (word of mouth). 
Product attributes are characterized with the parameters price, environmental friendliness and service-orientation. Based on the configuration of these attributes the overall utility of a product on the market is determined on individual agent level.

Customer agents are characterized with socio-demographic factors as well as individual sensitivity towards advertisement and word of mouth. This also includes the current satisfaction state, the frequency of communication (how many times) and the content of communication (what subject). Furthermore, each customer agent holds an awareness parameter for each product attribute per offer on the market.

The temporal and spatial units are the technical parameters defining elementary performance of the simulation. The simulation area is defined as continuous space where the customer agents are positioned randomly. The dimensions of the continuous space consist of a square. The size of this square depends on the population size and is adjusted accordingly in order to maintain a constant density within the population (in this case representing the city of Stockholm). This is crucial since, among other socio-demographic factors, an agent's geographic location influences its individual network and utility of product offers (Fig. 1). The time proceeds in discrete steps where one time step represents one day.

\subsection{Process overview and scheduling}

The statechart at customer agent level is shown in Fig. 2. In the software of Anylogic statecharts are used to describe event-driven and time-driven behavior of agents. In Fig. 2 the states are connected with arrows (transitions) defining time and the state the customer agent is in as well as the conditions under which that customer agent will transit to another state. More detailed explanations about the states and transitions are added on the right-hand side of Fig. 2. After initialization of the population [steps 1)-3)], customer agents repeatedly pass through the need state 3), evaluation state 5) and use phase of either conventional sales 10), competitor sales 11), buy-back 12) or pay-per-use 13). At the end of each use phase the actual utility is calculated and compared with the expected utility resulting in updated expectations when evaluating offers recurrently.

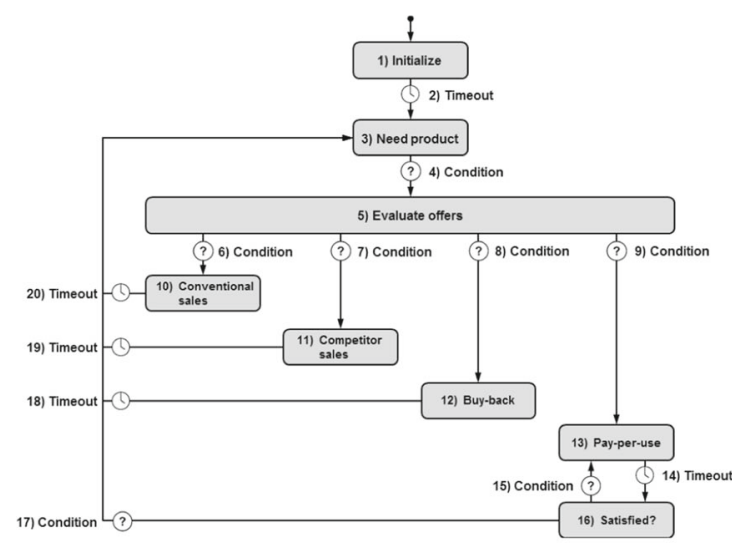

Fig. 2 Statechart for customer agents

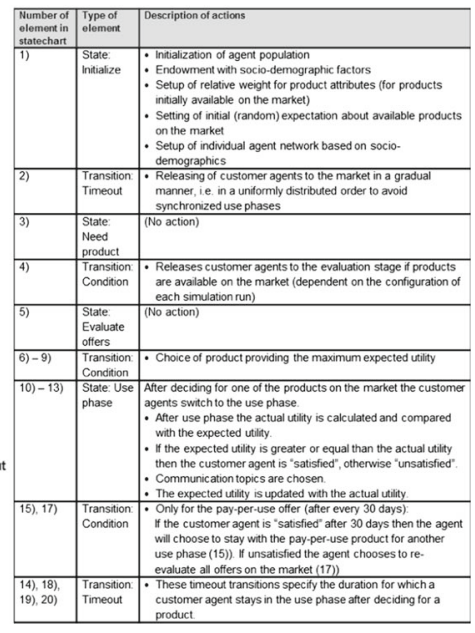




\subsection{Design concepts}

\subsubsection{Basic principles}

The overall modeling concept has been described in Sect. 3 comprising all relevant contents of the model design.

\subsubsection{Emergence}

The emerging demand for new (circular) product offers is quantified as a result of specific products advertised on the market and customer preferences resulting from the connection of socio-demographic factors, product utility, individual networks and communication aspects.

\subsubsection{Adaptation}

One adaptive trait is the awareness of product attributes which creates expectations. If one customer agent becomes aware of a product attribute and chooses to talk about it then this attribute is selected as communication subject. Other customer agents receiving information about this attribute will be made aware in case they receive information about it for the first time. Furthermore, during this event of communication customer agents also exchange their values on expected utility and relative importance of a product attribute (corresponding concepts are introduced in Sect. 4.6). The extent to which these two factors are adopted depends on the parameters susceptibility to advertisement and follower tendency [12]. Susceptibility to advertisement stands for the perceived influence through advertisement while follower tendency stands for the perceived influence through inter-agent communication.

\subsubsection{Objectives}

Each customer agent's objective is to decide for the product offer on the market providing the maximum expected utility, which is quantified as sum of all part worth utilities $u_{j_{\text {exp }}}$ resulting from product attributes $j$ of a product. The maximum value of each of the part worth utilities $\left(u_{j_{\max }}\right)$ is normalized with 1 . Then, the overall expected utility $U_{\exp }$ for each offer $P$ can be described assuming a classic additive utility function:

$$
U_{P_{\text {exp }}}=\sum_{j=1}^{n} u_{j_{\text {exp }}}
$$

\subsubsection{Learning}

After the use phase the expected and the actual utility of each customer agent are compared to determine if the expectations after purchase and use have been met. If the overall actual utility of a product offer is greater than the overall expected utility the customer agent is classified as satisfied (otherwise unsatisfied). As a result of this post-purchase learning experience the current expected utility of that product is updated with the actual utility, which is then being considered in the following purchasing decision process. 


\subsubsection{Prediction}

The expected utility for a product offer is a customer agent's predictive value for anticipated utility. Each customer agent will chose the product offer that provides the highest expected utility, which then is compared to the actual value at the end of each use phase. The initial expected part utility $u_{j_{\text {exp }}}$ of an attribute is a random part utility between zero and $u_{j_{\max }}$.

\subsubsection{Sensing}

The sensing of customer agents among themselves requires that one customer agent initiates communication triggered by a periodically scheduled communication event. This event chooses a random number of communication partners from each single customer agent's network (receivers) and sends a message to each of them (sender). If a product attribute is chosen as communication subject the sender send its information about it, such as awareness and expected utility, to the receivers. The customer agents receiving this message process the information that the sender has provided and in turn send a message back to the sender including their own communication subjects and contents. At this point an agent ID verifier has been incorporated in order to ensure that pairs of customer agents only send and receive their message once to avoid infinite sender-receiver loops.

\subsubsection{Interaction}

Customer agents are exposed to two external stimuli (Fig. 1). The first stimuli concerns the information exchange between customer agents based on their experience, which includes sensing as described in Sect. 4.4.7. For the second stimuli which is the interaction of customer agents with advertisement from manufacturing it is assumed that advertisement of a product attribute $j$ is associated with a particular effectiveness, thus reaching only a fraction of the customer agent population per time.

\subsubsection{Stochasticity}

The most relevant stochastic processes in the ABM are the socio-demographic factors of the customer agent population, which are replicated based on statistics from the population in Stockholm. The two parameters follower tendency and susceptibility to advertisement are uniformly distributed across the entire customer agent population.

\subsubsection{Observation}

The data collected from all simulation runs are the aggregated number of customer agents in each use phase in order to identify the market shares of each product on the market over time. In parallel the diffusion of each product attribute for each product on the market is visualized as well as the count for communication occurrences per product attribute. The switching behavior from one to another product is also captured. In addition, the customer (dis)satisfaction is measured for the entire population over time. With this data thorough analysis of customer behavior can be carried out. 


\subsection{Initialization}

Before starting the simulation, statistics about the target population have been assigned which in this case described the city of Stockholm. This includes adjustment of the population density. The Weibull distributions for the socio-demographic factors are assigned as well as the behavior curves (introduced in Sect. 4.6.1). For each simulation run it needs to be determined what products and attributes are available from simulation start and what products and attributes will be added or changed during the course of the simulation (timing and intensity). The distribution of initially satisfied agents is specified as well.

\subsection{Submodels}

This section introduces the submodels as main development of this work which have been presented as underlying factors and influences in Fig. 1.

\subsubsection{Socio-demographic factors and behavior curves}

The socio-demographic factors are used to form the initial perceived weight of product attributes price, environmental friendliness and service-orientation. The forming of initial expected utility for a product attribute occurs as a result of behavior curves at population level. The case company Gorenje has been involved at this point as one of the stakeholders of this ABM to provide input about assumed customer perception about each of the three product attributes. Given the hypothetical scenario of a circular business approach it has been e.g. stated that "very young and very old customers will favor service-orientation more than middle-aged customers". The underlying assumption in this example is that younger customers will favor easy access over ownership while older customers will favor convenience in terms of service. Based on this exercise the relative importance of circular product attributes could be mapped as an index $i$ along the entire range of each socio-demographic factor. In doing so, a unit interval ranging from zero to one $[0,1]$ is used while one stands for the maximum perceived importance and zero for no importance of any product attribute $j$. Figure 3 gives an overview of how attribute indices for price $\left(i_{p}\right)$, environmental friendliness $\left(i_{e}\right)$ and service-orientation $\left(i_{s}\right)$ have been mapped for the socio-demographic factors income, age and education. To aggregate across all socio-demographic factors all attribute indices are added in order to obtain aggregated attribute index $I$ per product attribute $j$ :

$$
I_{j}=\sum_{d=1}^{n} i_{d}
$$

The example in Fig. 3 results in the formation of individually perceived weight $w$ for the attributes price $\left(w_{p}\right)$, environmental friendliness $\left(w_{e}\right)$ and service-orientation $\left(w_{s}\right)$. The weight $w$ of product attribute $j$ of any customer agent can be formulated as:

$$
w_{j}=\frac{I_{j}}{\sum_{j=1}^{n} I_{j}}
$$

It should be noted that the geographic location is solely included for the creation of network structures. The example in Fig. 3 shows a case in which one customer agent is aware of all three product attributes. If the same customer agent is not aware of e.g. environmental friendliness and service-orientation the weight for $w_{p}$ would have been 1 whereas $w_{e}$ and $w_{s}$ 


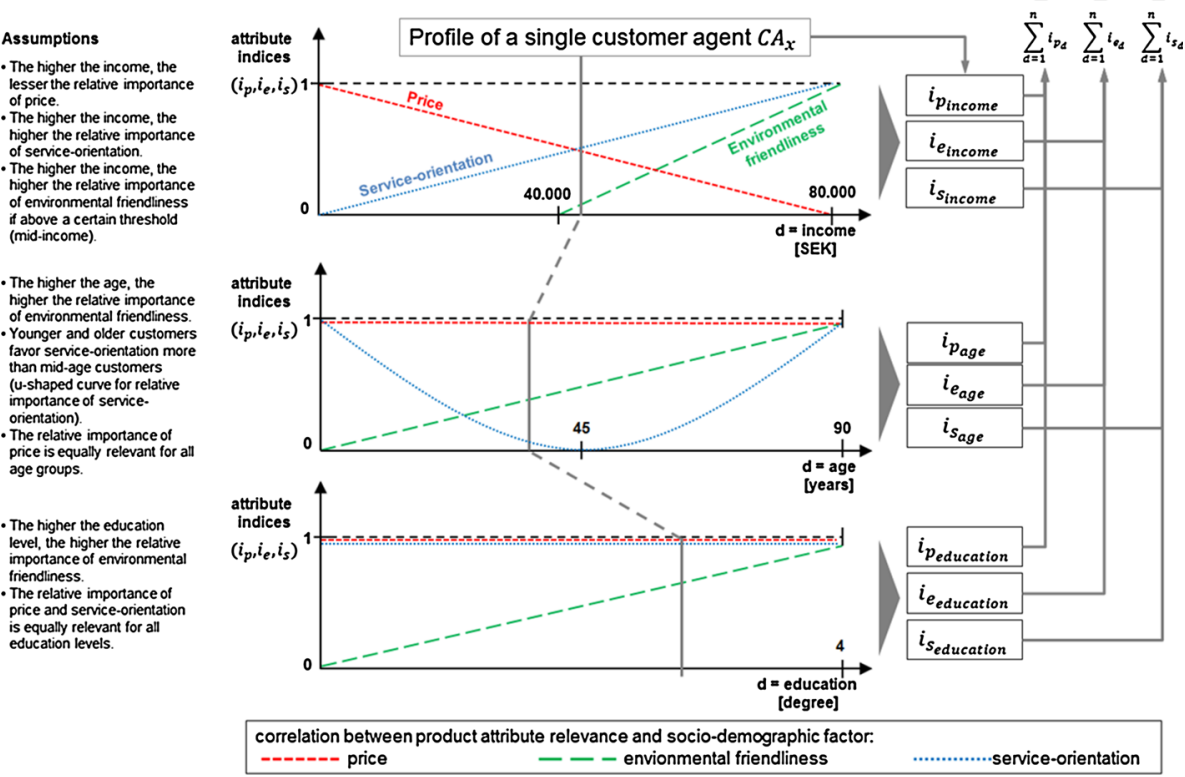

Fig. 3 Behavior curves using attribute indices price $\boldsymbol{i}_{\boldsymbol{p}}$, environmental friendliness $\boldsymbol{i}_{\boldsymbol{e}}$ and service-orientation $i_{s}$ for socio-demographic factors income, age and education (elaborated in collaboration with the case company Gorenje for washing machines)

would have been 0 , since price in this case would have been perceived as the only relevant criteria by the customer agent.

On the left-hand side of Fig. 3 assumptions are listed which led to the shape of the behavior curves. In this model the target population is a Swedish population in the city area of Stockholm.

\subsubsection{Expected and actual part utilities}

Part worth utilities are formed for each of the attributes price, environmental friendliness and service-orientation. In order provide each customer agent with random expectations at simulation start, the initial expected part utility $u_{j_{\text {exp }}}$ for each agent is a random part utility between zero and $u_{j_{\max }}$ generated through multiplication of a random number $r$ (from a uniform distribution ranging from zero to one) with the agent's individual perceived weight $w_{j}$ and $u_{j_{\max }}$.

$$
u_{j_{\text {exp }}}=w_{j} \cdot r \cdot u_{j_{\max }}
$$

The maximum value of each of the part utilities $\left(u_{j_{\max }}\right)$ is normalized with 1 . After the use phase the expected and the actual utility are compared in order to identify if expectations of the product have been met. As a result of the post-purchase experience the expected utility is updated with the actual utility at the end of each use phase, i.e.

$$
U_{\text {exp }}=U_{\text {actual }}
$$


Table 1 Summary of generic part utility functions for product attributes price, environmental friendliness and service-orientation

\begin{tabular}{lll}
\hline Product attribute $\mathrm{j}$ & $\begin{array}{l}\text { Part worth utility function } \\
u_{j}(j)\end{array}$ \\
\hline Price $(p)$ & $u_{p}(p)=u_{p_{\max }} \cdot\left(1-\frac{p}{p_{\max }}\right)$ \\
Environmental impact $(e)$ & $u_{e}(e)=u_{e_{\max }} \cdot \frac{e}{e_{\max }}$ & $\begin{array}{l}\text { Graph of part worth utility } \\
\text { function } u_{j}(j)\end{array}$ \\
Service-orientation $(s)$ & $u_{S}(s)=u_{s_{\max }} \cdot \frac{s}{s_{\max }}$ & \\
$\longrightarrow$
\end{tabular}

Customer agents can influence each other's expectations of an attribute $u_{j_{\text {exp }}}$ if that attribute is chosen as subject for communication. Thus, as the number of agents and their parameters does not change during simulation the same customer agents can be exposed to the same market situation with changing expected utility but unchanged product offer. This feature enables the possibility to consider repeated purchase decisions of customer agents.

Actual part utilities including price, environmental friendliness and service-orientation are determined based on part utility functions as shown in detail in Table 1 . These functions are generic for the entire customer population and are based on the case company's perception. At this point it is assumed for the Stockholm market that, while considering attributes independently, price increases tend to result in lower utility for customers. On the other hand, increases in environmental friendliness and service-orientation tend to result in higher utility.

Part utilities $u_{j}(j)$ as a result from these generic functions in Table 1 are multiplied with the agent's individual weight for the respective product attribute $w_{j}$ to reflect individual perception of that attribute after purchase. The actual overall utility $U_{P_{\text {actual }}}$ of a product offer $P$ after use can be expressed as sum of its weighted utilities:

$$
U_{P_{\text {actual }}}=\sum_{j=1}^{n} w_{j} \cdot u_{j}(j)
$$

\subsubsection{Social network structure}

By applying the concept of homophily the probability of information exchange between two individuals depends on the similarity of their socio-demographic factors [10]. In comparison to a distance-based network this brings the advantage that inter-agent connections can occur throughout the entire continuous modeling space since geographic distance is not the only measure for (dis)similarity. Furthermore, a network structure based on homophily appears more realistic as well as more practical since socio-demographic data are already applied 
in Sect. 4.6.1 (behavior curves) in order to characterize customer agents. So, the network creation is based on the social (dis)similarity $s$ and defined as Euclidean distance $D$ in all dimensions $d$ (number of socio-demographic factors) [9]. Formally, the (dis)similarity between two customer agents $x$ and $y$ can be expressed as follows:

$$
s_{x y}=\sqrt{\sum_{k=1}^{n}\left(\frac{d_{x_{k}}-d_{y_{k}}}{\max D_{k}}\right)^{2}}
$$

where $d_{x_{k}}$ and $d_{y_{k}}$ are the socio-demographic factors $k$ for each of the two agents $x$ and $y$, and $\max D_{k}$ is the maximum distance of the socio-demographic factor $k$ across the entire customer population. A connection between the two agents $x$ and $y$ is established if a random number $r$ following a uniform distribution falls below the following similarity tie weight $\theta_{x y}$ :

$$
\theta_{x y}=1-\left(\frac{s_{x y}}{\max s}\right)
$$

To give an example, if both of the two customer agents $x$ and $y$ have the same sociodemographic factors, then $s_{x y}$ results in the value zero which in turn leads to a value of one for $\theta_{x y}$. Fixing the range of $r$ to be between 0 and 1 would mean a probability of $100 \%$ that customer agents $x$ and $y$ would create a bond. The emerging network is static, i.e. once it is initialized in the beginning of the simulation it is not changing over time.

\subsubsection{Communication rationale and information exchange}

A product attribute is chosen as subject for communication if the expected part utility of that product attribute is higher than the actual part utility at the end of the product use phase. For "satisfied" customer agents the probability of choosing a subject for communication depends on how much the actual utility of an attribute exceeds the expected part utility. The underlying assumptions on communication subjects is that negative experiences are always communicated [23] while positive experiences are communicated only to a certain extent. To give an example, in the moment of communication between two agents $x$ and $y$ their attribute weight and expectations are updated which can be formalized as:

Customer agent $x$ :

$$
u_{x, j_{e x p}}=u_{x, j_{e x p}}+f t_{x}\left(u_{y, j_{e x p}}-u_{x, j_{e x p}}\right)
$$

and

$$
w_{x, j}=w_{x, j}+f t_{x}\left(w_{y, j}-w_{x, j}\right)
$$

Customer agent $y$ :

$$
u_{y, j_{e x p}}=u_{y, j_{e x p}}+f t_{y}\left(u_{x, j_{e x p}}-u_{y, j_{e x p}}\right)
$$

and

$$
w_{y, j_{\text {exp }}}=w_{y, j_{\text {exp }}}+f t_{y}\left(w_{x, j_{\text {exp }}}-w_{y, j_{\text {exp }}}\right)
$$

In order to model a realistic effect of information exchange the decay of information content over time is considered. This allows for customer agents to return their original, i.e. intrinsic, values of expectation after an interaction event. Thus, it is assumed that the impact of information content declines over time which is considered through $e^{-\sigma \cdot t}$ where $t$ is the current simulation time and $\sigma$ an exponential information decline factor. Assuming the interaction 
of agent $x$ with agent $y$ occurs at $t$ while agent $x$ has been exposed to advertisement at $t-z$, then the update of agent $x$ 's expected part utility at $t$ can be calculated as:

Customer agent $x$ at $t-z$ :

$$
u_{x, j_{\text {exp }}}=u_{x, j_{\text {exp }}}+\left(f t_{x}\left(u_{y, j_{\text {exp }}}-u_{x, j_{\text {exp }}}\right)\right) \cdot e^{-\sigma \cdot t}+\left(\operatorname{sus}_{x}\left(u_{j_{\max }}-u_{x, j_{\text {exp }}}\right)\right) \cdot e^{-\sigma \cdot(t+z)}
$$

Customer agent $y$ (not having been exposed to advertisement):

$$
u_{y, j_{\text {exp }}}=u_{y, j_{\text {exp }}}+\left(f t_{y}\left(u_{x, j_{\text {exp }}}-u_{y, j_{\text {exp }}}\right)\right) \cdot e^{-\sigma \cdot t}
$$

Note that with each single event of interaction the information value decline $e^{-\sigma \cdot t}$ starts with a count at $t=0$.

\section{Business case description}

\subsection{Strategic scenario}

The simulation time encompasses 20 years in total (corresponding to 3 use cycles for washing machines) in order to account for sufficient washing machine purchases. During the first 5 years the simulation endows all customer agents with purchasing experiences of one washing machine. In doing so each customer agent updates its expectations about the available offers on the market as a setup before other offers are introduced. It is assumed that all offers are instantly available. All initial main variables, sources of data and initial values are summarized in Table 2. The distributions of the socio-demographic factors age, income, education and geographic location are based on publicly available information [30-32]. Table 3 provides an overview with what product offers and corresponding constellation of attribute values the market is entered.

\subsection{Conventional sales and competition}

Starting from an initial linear scenario, which represents a business-as-usual case, a competitive market is assumed and represented by one conventional sales offer and one competitive offer. Both offers differ in price and are marketed with price attribute only.

\subsection{The buy-back offer}

The buy-back offer is similar to the conventional sales offer, but furthermore includes a buyback option in which customers have the opportunity to sell the washing machine back to the producer. The buy-back price of the washing machine is considered as a percentage of the purchasing price. With respect to the possibility that a customer might not return washing machines despite the buy-back option (due to convenience of not returning or preference of ownership), it is assumed that the closer the buy-back price to the original sales price, the higher the probability of a washing machine being returned. If a customer agent decides to return its washing machine then the buy-back price is paid to the customer at the end of the use period. In this case the actual part utility of the product attribute price is adjusted accordingly (Eq. 6).

To gain improved control regarding returning washing machines for the buy-back offer an increased buy-back price of $15 \%$ (instead of 10\%) of the original price is linked to the 
Table 2 Main variables, sources of data, initial values of the main variables and their units of measure

\begin{tabular}{|c|c|c|c|}
\hline Main variables & $\begin{array}{l}\text { Sources of data used for } \\
\text { initial values as input }\end{array}$ & Initial values & Unit of measure \\
\hline Population size & Assumed & 10.000 & Agents \\
\hline $\begin{array}{l}\text { Income (Weibull } \\
\text { distribution) }\end{array}$ & Statistics Sweden (2014) & $\begin{array}{l}\alpha: 1.6 \\
\beta: 3.0 \\
\text { Minimum: } 0 \\
\text { Multiplication factor: } \\
10,000\end{array}$ & SEK \\
\hline Age (Weibull distribution) & $\begin{array}{c}\text { City municipality of } \\
\text { Stockholm (2014) }\end{array}$ & $\begin{array}{l}\alpha: 2.0 \\
\beta: 4.0 \\
\text { Minimum: } 0 \\
\text { Multiplication factor: } 10\end{array}$ & Years \\
\hline $\begin{array}{l}\text { Education (Weibull } \\
\text { distribution) }\end{array}$ & Statistics Sweden (2014) & $\begin{array}{l}\alpha: 3.0 \\
\beta: 1.9 \\
\text { Minimum: } 0 \\
\text { Multiplication factor: } 1\end{array}$ & Degree type \\
\hline $\begin{array}{l}\text { Population density } \\
\text { Stockholm urban area } \\
\text { (continuous space) }\end{array}$ & Statistics Sweden (2012) & 3597 inhabitants $/ \mathrm{km}^{2}$ & $\mathrm{~m}^{2}$ \\
\hline $\begin{array}{l}\text { Maximum willingness to } \\
\text { pay for a washing } \\
\text { machine }\end{array}$ & $\begin{array}{l}\text { Company input } \\
\text { (Gorenje d.d.) }\end{array}$ & $\begin{array}{l}25,000 \\
\text { (equivalent to } \\
300 \mathrm{SEK} / \text { month for } 7 \\
\text { years) }\end{array}$ & SEK \\
\hline $\begin{array}{l}\text { Best perceived } \\
\text { environmental impact }\end{array}$ & $\begin{array}{l}\text { Company input } \\
\text { (Gorenje d.d.) }\end{array}$ & $\begin{array}{l}\text { 1: Product is } \\
\text { environmentally } \\
\text { friendly (Boolean scale) }\end{array}$ & Unitless \\
\hline $\begin{array}{l}\text { Highest perceived service } \\
\text { level }\end{array}$ & $\begin{array}{l}\text { Company input } \\
\text { (Gorenje d.d.) }\end{array}$ & $\begin{array}{l}\text { 2: Maintenance \& } \\
\text { Flexibility to change } \\
\text { product anytime } \\
\text { (discrete scale) }\end{array}$ & Unitless \\
\hline $\begin{array}{c}\text { Susceptibility to } \\
\text { advertisement }\end{array}$ & Assumed & $\begin{array}{l}\text { Uniform distribution } \\
\quad(0-1) \\
\text { 0: no susceptibility } \\
\text { 1: full susceptibility }\end{array}$ & Unitless \\
\hline Follower tendency & Assumed & $\begin{array}{l}\text { Uniform distribution } \\
\quad(0-1) \\
0 \text { : no influence } \\
\text { 1: full influence }\end{array}$ & Unitless \\
\hline $\begin{array}{l}\text { Ownership tendency } \\
\text { (fraction of population) }\end{array}$ & Assumed & 0.25 & Percent \\
\hline $\begin{array}{l}\text { Effectiveness/reach of } \\
\text { advertisement }\end{array}$ & $\begin{array}{l}\text { Company input } \\
\text { (Gorenje d.d.) }\end{array}$ & 0.05 & Percent/month \\
\hline $\begin{array}{l}\text { Communication } \\
\text { frequency of customer } \\
\text { population }\end{array}$ & Assumed & $\begin{array}{l}\text { Uniform distribution } \\
(0-1)\end{array}$ & Times/month \\
\hline
\end{tabular}


Table 3 Product offers and their attribute values for washing machines (WMs)

\begin{tabular}{|c|c|c|c|c|}
\hline Attribute & Conventional sales & Competitor sales & Buy-back & Pay-per-use \\
\hline Price & $\begin{array}{l}\text { 12,000 SEK/WM } \\
\text { (use phase } 7 \text { years) }\end{array}$ & $\begin{array}{l}8000 \text { SEK/WM } \\
\text { (use phase } 5 \text { years) }\end{array}$ & $\begin{array}{l}\text { 12,000 SEK/WM } \\
\text { (use phase } 7 \text { years) } \\
\text { (Buy-back price: } \\
10 \% \text { of original } \\
\text { price) }\end{array}$ & $\begin{array}{l}300 \mathrm{SEK} / \mathrm{month} \\
\text { (use phase } 30 \text { days) }\end{array}$ \\
\hline $\begin{array}{l}\text { Environmental } \\
\text { friendly }\end{array}$ & No & No & Yes & Yes \\
\hline \multirow{2}{*}{$\begin{array}{l}\text { Service- } \\
\text { orientation }\end{array}$} & No service & No service & No service & 1) Full maintenance \\
\hline & & & & $\begin{array}{l}\text { 2) Flexibility to } \\
\text { change WM }\end{array}$ \\
\hline
\end{tabular}

condition that the return occurs within 3 years. In doing so, the return probability of washing machines after 3 years is increased with an attempt to ensure the beginning of diffusion of buy-back attributes the latest after the third year.

\subsection{The pay-per-use offer}

For the pay-per-use offer it is assumed that customers receive a washing machine including free installation at home and are then charged on a monthly basis. This service-based arrangement can be terminated anytime upon request. Hence, after a period of 30 days each customer agent evaluates its satisfaction by comparing its expected and actual utility of the acquired pay-per-use arrangement. In case of a satisfactory outcome the customer agent chooses to stay with the current arrangement until re-evaluation in another 30 days. In case of an unsatisfactory evaluation result the customer agent terminates the arrangement.

\subsection{Advertisement and diffusion}

The diffusion of the buy-back and pay-per-use offer is triggered by initial advertisement containing information about product attributes. It is assumed that $5 \%$ of the population is reached during an advertisement period of 30 days. The buy-back offer is advertised with the attributes price and environmental friendliness while the pay-per-use is advertised with the attributes price, environmental friendliness and service-orientation.

\section{Simulation results}

Three distinct simulation runs have been performed. Firstly, the buy-back and pay-per-use scenarios are tested separately. I.e. each offer is launched at year $5(t=1827$ days $)$ in parallel to the conventional and competitive offer and analyzed independently using the criteria market share, customer satisfaction, diffusion of attributes and communication occurrences. Afterwards, a combined scenario is run in which both, buy-back and pay-per-use offer, are launched with their product attributes at different points in time. This final scenario is analyzed with respect to the same criteria as mentioned above. 30 replications were performed for each of the three scenarios. A single simulation run takes approximately $10 \mathrm{~min}$ and creates more than 7 million event logs. 


\subsection{Simulation run 1: buy-back versus linear}

Until $\mathrm{t}=1827$ days only conventional sales and competitive sales are available at the market endowing customer agents with initial purchase experience. In this ramp-up phase of the simulation run (between $\mathrm{t}=500$ and $\mathrm{t}=2500$ days) unexperienced customers first need to adapt to the two offers on the market. The simulation starts with a 50/50 distribution of satisfied/unsatisfied customers and expectations (expected utilities) are initially random (Eq. 6). As a result, first user experiences differ greatly from expectations, thus triggering communication while turning increasingly unsatisfied. The level of unsatisfactory customers after start-up peaks at $\mathrm{t}=2500$ days and then returns to the distribution of 50/50 satisfied/unsatisfied customers. Tests of the linear baseline scenario can be found in the online resource 1 .

The buy-back offer is introduced at $t=1827$ days with the attributes price and environmental friendliness. The first 3 years after introduction (at roughly $t=3000$ days) only a small fraction of customers get attracted. This seems to be the fraction which has been made aware through advertisement at $\mathrm{t}=1827$ (see Fig. 4a, c). Results indicate that the increased buy-back price of $15 \%$ of the initial purchasing after a use period of 3 years reinforces the diffusion of the buy-back attributes starting at around $t=3000$. Here the price of the buyback offer is the most important communication subject and diffusing rather fast as shown in Fig. 4c, d. The product attribute environmental friendliness remains relatively unimportant within the population. This is in line with the assumption about the behavior curves modeled in Sect. 4.6.1.

At around $t=5500$ days more customer turn unsatisfied. The reason for the increasing dissatisfaction is the delayed diffusion of the product attribute environmental friendliness. In this process of delayed and gradual diffusion expectations for the buy-back offer are increased but do not seem to be met. Nevertheless, buy-back remains the most attractive offer on the market as the price at the end of the use phase seems to have a compensating effect. This also

(a) Market share

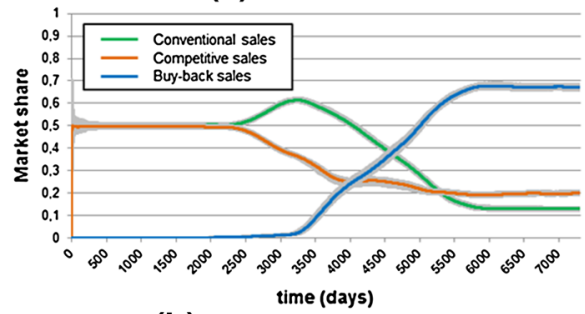

(b) Customer satisfaction

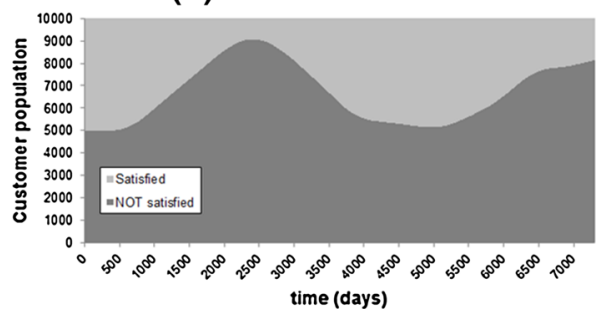

(c) Attribute diffusion buy-back

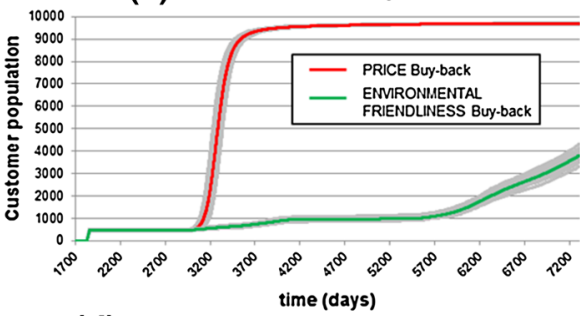

(d) Communication occurrences buy-back

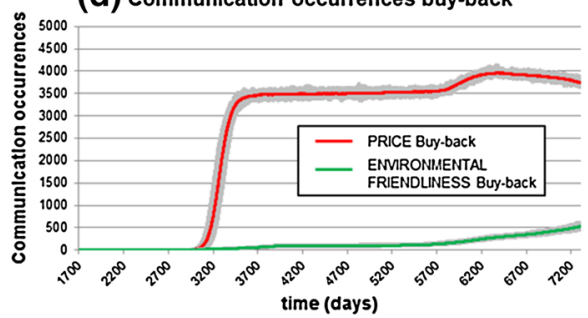

Fig. 4 Average simulation results after 30 replications (in grey) for buy-back scenario with launch at $\mathrm{t}=$ 1827 days (5 years) including market share (a), customer satisfaction (b), diffusion of product attributes (c) and communication occurrences per product attribute $(\mathbf{d})$ 
(a) Market share

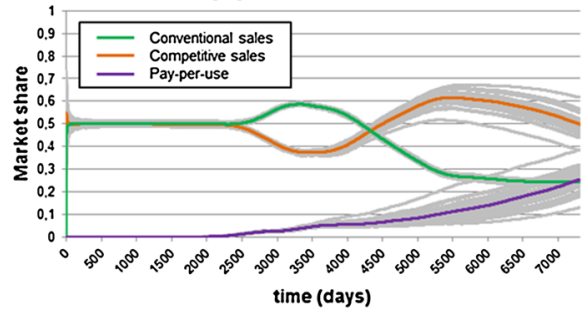

(b) Customer satisfaction

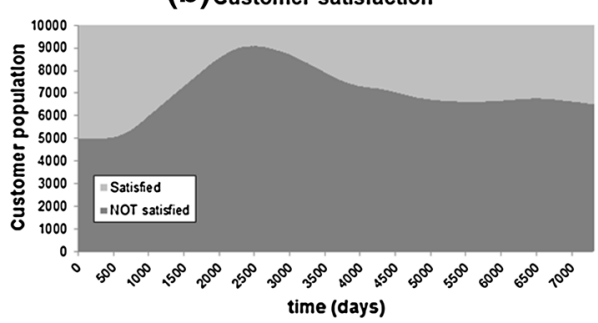

(c) Attribute diffusion pay-per-use

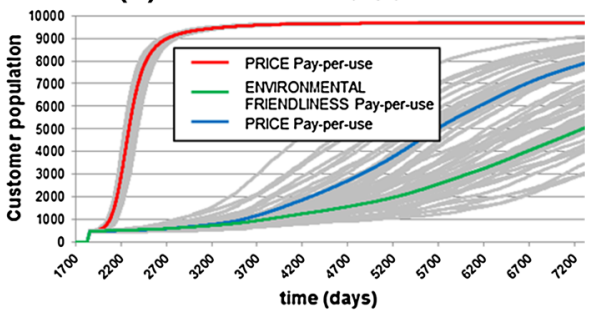

(d) Communication occurrences pay-per-use

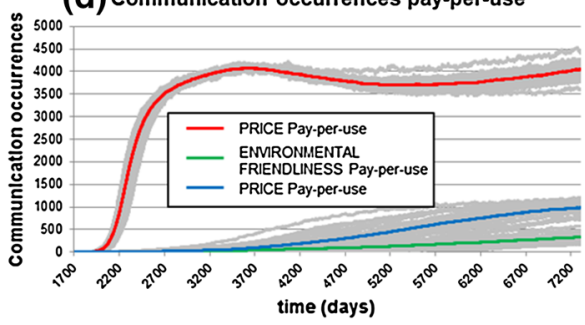

Fig. 5 Average simulation results after 30 replications (in grey) for pay-per-use scenario with launch at $\mathrm{t}=$ 1827 days (5 years) including market share (a), customer satisfaction (b), diffusion of product attributes (c) and communication occurrences per product attribute $(\mathbf{d})$

explains the slight increase of communication occurrences for the price attribute after $\mathrm{t}=$ 5700 days. As a consequence, the overall market share of the buy-back offer remains stable even though the satisfaction level changes. Extending the simulation run time would exhibit the complete diffusion of the attribute environmental impact and its consequences.

\subsection{Simulation run 2: pay-per-use versus linear}

Only launching the pay-per-use offer at $t=1827$ with the attributes price, environmental friendliness and service-orientation demonstrates a rather immediate diffusion of the price attribute Fig. 5c. Similarly as for the buy-back offer, the attributes service-orientation and environmental friendliness diffuse rather gradually and seem less relevant, which is aligned with the underlying behavior curves modeled in Sect. 4.6.1. Diffusion and communication about the product attributes environmental friendliness and service-orientation show greater variation during several simulation runs. The variations are caused by different network structures which are newly created at the start of every simulation run. In addition, the payper-use offers are re-evaluated by the customers every 30 days. This leads to more frequent updates of experiences and communication subjects over time and a more spread and less controllable diffusion compared to the buy-back offer. Given the variations in market share for the competitive offer and the pay-per-use offer in Fig. 5a as well as the diffusion curves in Fig. 5c indicate that an earlier diffusion of the two attributes environmental friendliness and service-orientation might be decisive for customers to switch from competitive to the pay-per-use offer.

\subsection{Simulation run 3: buy-back \& pay-per-use versus linear}

In this simulation run both buy-back and pay-per-use offer are consecutively introduced on the market. Figure $6 \mathrm{a}-\mathrm{f}$ shows the corresponding simulation results for introducing buy-back 
(a) Market share

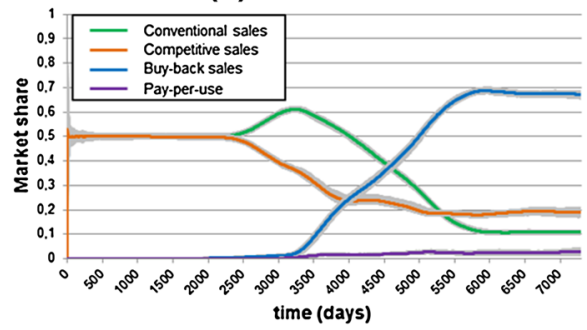

(c) Attribute diffusion buy-back

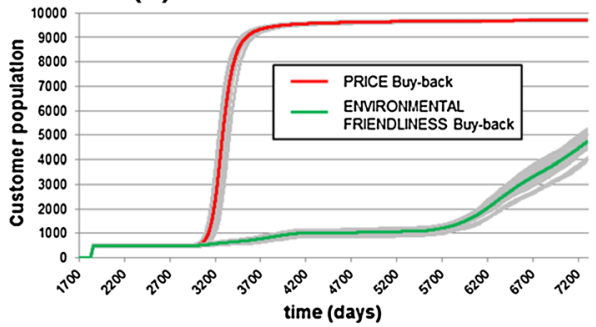

(d) Communication occurrences buy-back

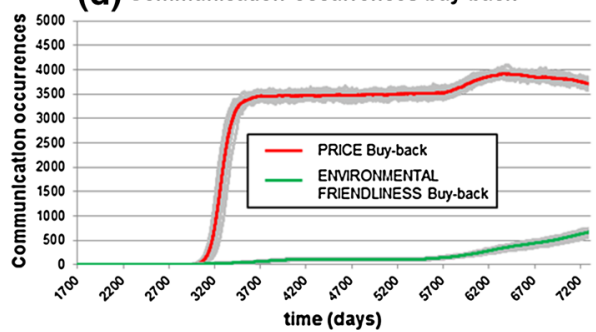

(b) Customer satisfaction

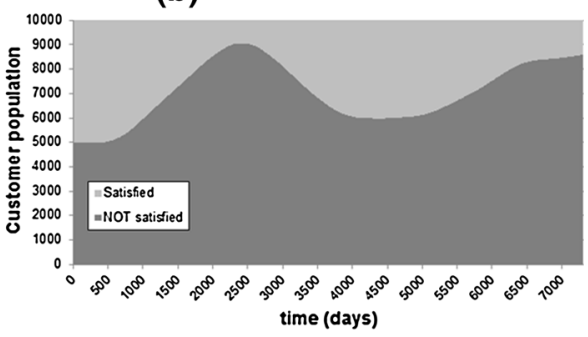

(e) Attribute diffusion pay-per-use

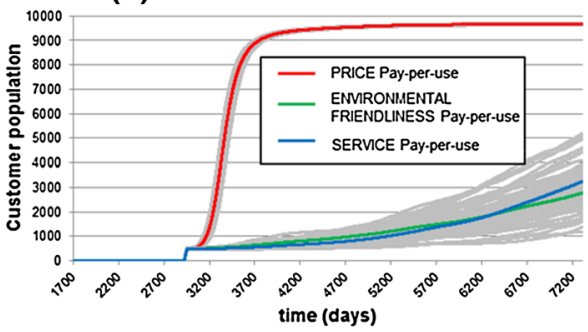

(f) Communication occurrences pay-per-use

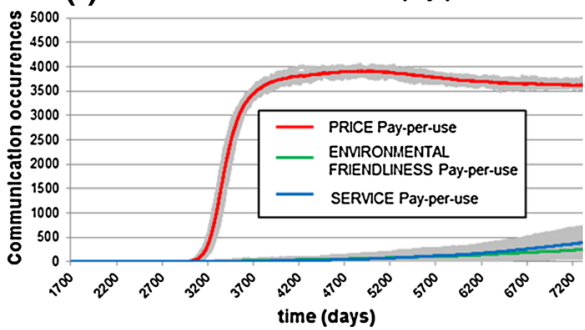

Fig. 6 Average simulation results after 30 replications (in grey) for a combined scenario of launching a buyback offer at $t=1827$ days (5 years) and a pay-per-use offer at $t=2922$ days (8 years) including market share (a), customer satisfaction (b), diffusion of product attributes $(\mathbf{c}, \mathbf{e})$ and communication occurrences per product attribute $(\mathbf{d}, \mathbf{f})$

at $\mathrm{t}=1827$ days ( 5 years) and pay-per-use at $\mathrm{t}=2922$ days ( 8 years). It is worthwhile to note that the buy-back offer and the competitive offer acquire the same market share compared to the scenario simulation run 1 (see Figs. 4a, 6a). From an overall perspective the effects of the buy-back offer remain almost identical compared to simulation run 1, while the effect of the pay-per-use offer on the customer population appears to be reduced. Compared to simulation run 2 the market share gain of the pay-per-use offer is relatively small. Main reason appears to be the gradual diffusion of the attributes environmental friendliness and service-orientation in combination with a late market launch, which seem to impede the adoption of the pay-peruse offer. The customer behavior in terms of switching between the offers over time is shown in Fig. 7. It shows that the high demand for the buy-back offer comes from all other three products and is gaining large market share in relatively short time (Fig. 7c, g). Long-term adoption of the buy-back offer is reached at $t=5800$ days (Fig. $7 \mathrm{k}$ ). On the other hand, the pay-per-use offer is initially tested by customers, however after only a short time the largest share switches to buy-back and competitor sales (Fig. 7k, o). Hence, the adoption of the pay-per-use offer is gradually increasing (Fig. 7p) which might be due to rather slowly diffusing attributes. 

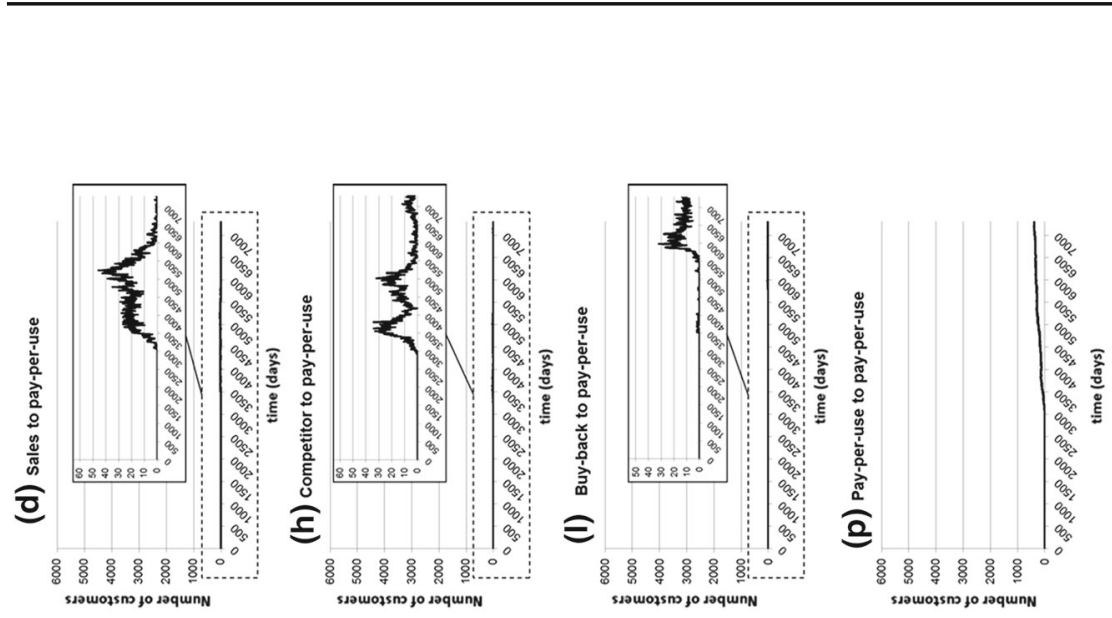

กิ
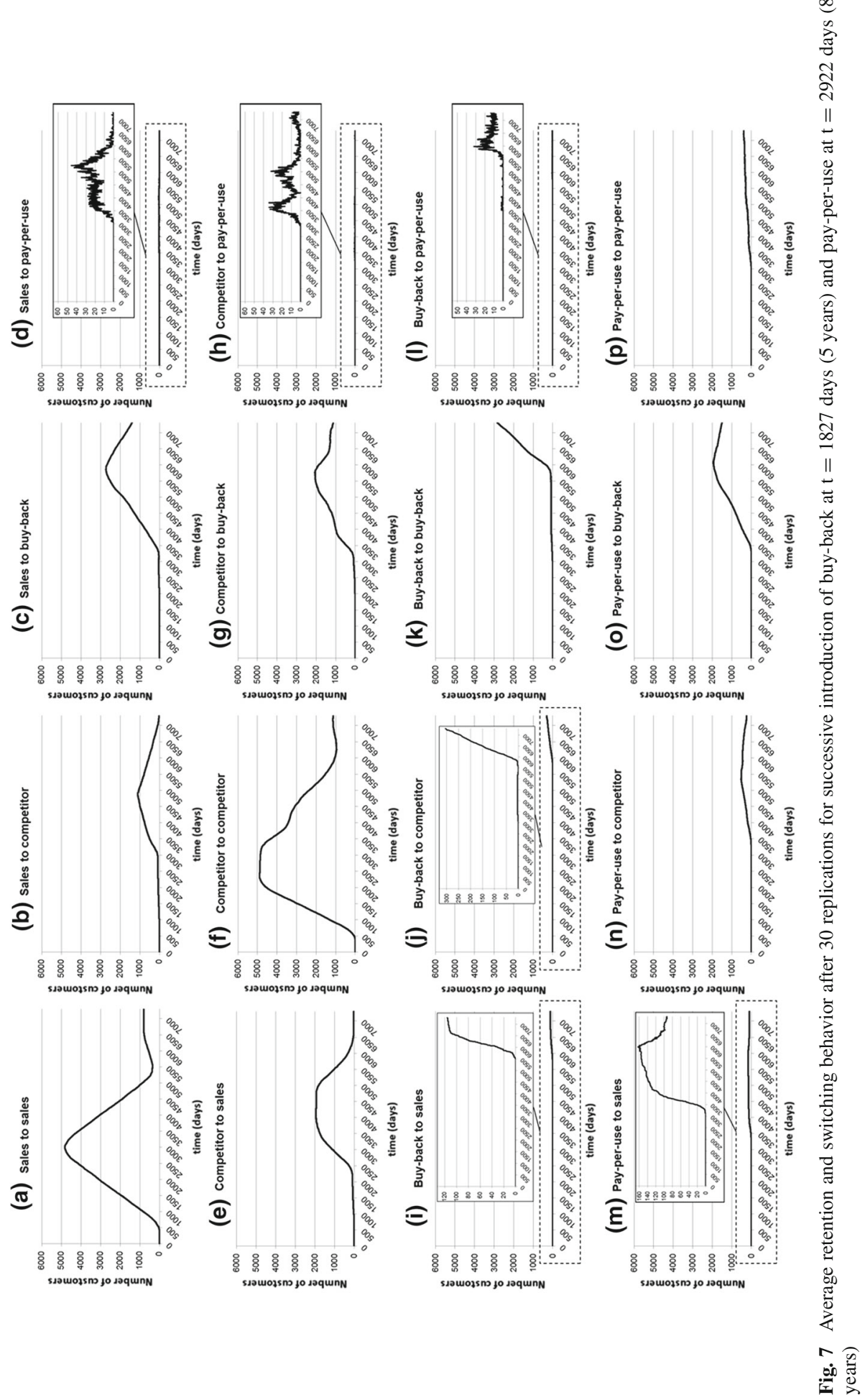
(a) Sensitivity analysis for pay-per-use price

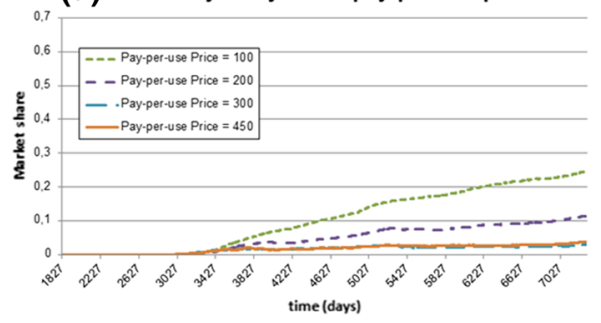

(C) Sensitivity analysis agent connections (buy-back)

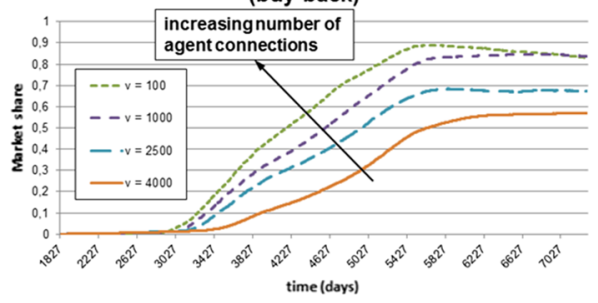

(b) Sensitivity analysis for agent adaptability (pay-per-use)

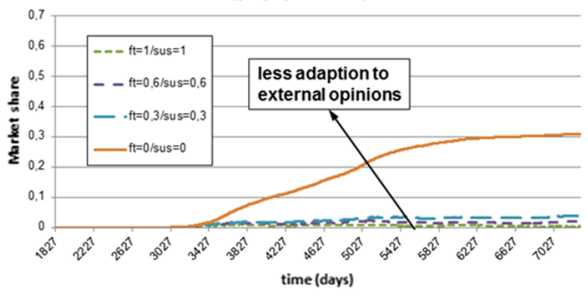

(d) Sensitivity analysis advertisement effectiveness (buy-back)

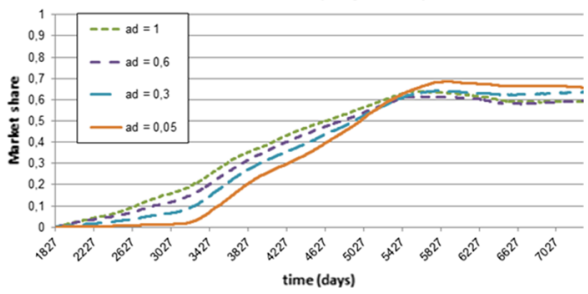

Fig. 8 Sensitivity analyses for a price levels, $\mathbf{b}$ agent adaptability, c agent connections, $\mathbf{d}$ effectiveness of advertisement

\subsection{Sensitivity analysis}

In order to evaluate the robustness of the results and furthermore identify major drivers as well as critical parameters sensitivity analyses have been carried out with regards to the following aspects: Customer population size, number of product attributes, price for pay-per-use offers, network structures, number of socio-demographic factors, agent adaptability, effectiveness of advertisement, buy-back price. At this point only most relevant findings are discussed. Detailed descriptions on each of the sensitivity analyses can be found in the online resource 1. All of the sensitivity analyses take the scenario from Sect. 6.3 as basis.

Price for pay-per-use offer

Experiments with various price levels of 450, 300, 200 and 100 SEK per month for the pay-per-use offer demonstrated that price is perceived as relevant attribute with direct impact on the market share (Fig. 8a). This is in line with the assumptions made regarding the behavior curves in Sect. 4.6.1 where price is the most relevant attribute compared to the other attributes across all socio-demographic factors.

\section{Social network structure}

This sensitivity analysis has been carried out by varying the number of connections between agents using a network factor (v), i.e. 4000, 2500, 1000 and 100, while keeping the population of customer agents at a constant of 10000. As can be seen in Fig. 8c a larger number of connections on individual agent level is leading to a faster adoption of the buy-back offer since a tighter network promotes a faster the diffusion of product attributes.

\section{Agent adaptability}

This sensitivity analysis has been carried out by varying values for the parameters follower tendency (ft) andsusceptibility to advertisement (sus), i.e. 0.0, 0.3, 0.6 and 1.0. Figure $8 \mathrm{~b}$ shows that the lower the adaption rate of external information, the higher the acceptance of the pay-per-use offer on the market. This is particularly the case for values below 0.3 . Hence, 
agents make different purchase decisions if they are interacting with each other. In the case of agent isolation ( $\mathrm{ft} / \mathrm{sus}=0$ ) agents compare offers solely based on their experience (actual utility). On the other hand, highly adaptive agents get affected/persuaded by their network that the buy-back offer provides more utility (increasing expectations) than the pay-per-use offer.

\section{Effectiveness of advertisement}

The effectiveness of advertisement has been tested by varying values for the parameters effectiveness of advertisement (ad) with values of $0.05,0.3,0.6$ and 1.0. The result in Fig. $8 \mathrm{~d}$ shows that, as expected, the adoption process is accelerated based on a faster diffusion of the product attributes.

\subsection{ABM validation}

According to Sterman [33] "no model can be verified or validated because all models are wrong". By this Sterman implied that "all models, mental or formal, are limited, simplified representations of the real world. They differ from the reality in ways large and small, infinite in number". However, some level of validation is necessary to elevate the confidence to claim that the model presented in this work generates reasonable results and behaviors of the model variables are rational. The model has been verified and validated following the procedures for model verification and model validation by Dam et al. [3]. Model verification focuses on correct implementation of computer code while model validation concerns whether the model is an accurate representation of the real-world system.

In order to ensure correct implementation of code tests have been performed during the implementation for each of the submodels. This includes single-agent testing in which utilities on individual level are checked based on utility functions and offers on the market to ensure agent utility yielded expected results. The interaction of agents has been tracked on individual level in order to guarantee that communication events have the expected effect based on adaptation rates (i.e. the parameters follower tendency and susceptibility to advertisement). Furthermore, recording and tracking of agent parameters has been performed in multi-agent networks for socio-demographic factors to ensure distributions within the agent population are properly replicated. Details on tests which have been performed can be found in the online resource 1. As a following step integration tests have been performed where the submodels were linked and run. Using specific parameter settings expected behavioral outcomes have been verified. To give examples, deactivating certain product attributes results in slower adoption, or the reduction of social networks will result in a lower number of communication occurrences.

Compared to model verification the model validation is more challenging since actual data about innovation diffusion in the context of CE currently do not exist and are therefore only available after its real-world event. Hence, neither historical data nor literature exists that could serve as reference point for the model validation. A market expert asserted that diffusion rates and market shares obtained from the model are reasonable. As a rather highlevel qualitative indication it can be observed that in each of the 3 simulation runs the diffusion curves of the price attributes reproduces typical S-shaped curve of innovation diffusion.

\subsection{Discussion}

This research introduces the first tool using ABM in the context of CE to study customer behavior as a consequence of business model changes. In association with the simulation 
results it appears that a systematic marketing strategy has the potential to accelerate customer acceptance and affect the transition time from linear to circular. In simulation run 3, which is a combination of different business models, the adoption of the pay-per-use offer can be improved by increasing intensity of advertisement for environmental friendliness and serviceorientation. Hence, marketing initiatives need to emphasize single $C E$ value propositions with different intensities.

The result of simulation run 3 also indicates that the launch of pay-per-use products can suitably be synchronized with buy-back offers to make returns more efficient (Fig. 6, $t=$ 3000 days). From a case company perspective, and assuming that the implementation of a buy-back infrastructure is less capital-intensive than for a pay-per-use infrastructure, it seems more feasible to initially introduce a buy-back offer to gain experience in take-back activities and introduce a pay-per-use offer after another 3 years. In this regard the planning of value recovery operations for washing machines can be facilitated with the result of this ABM. Systematic CE marketing as mentioned above is capable to influence quality, quantity and timing of product returns. Since this ABM also captures switching behavior of customers between the different offers, as highlighted in Fig. 7, degrees of adoption as well as the risks of product sales cannibalization can be estimated.

As a modeling approach ABMs seem highly capable of filling the gap between diffusion processes, i.e. the spreading and movement of information through populations, and resulting individual behavior. As demonstrated during the sensitivity analysis in Fig. 8b leaving influences between customers, i.e. network structures and communication events, unconsidered may result in different market shares. Given the nature of agent-based modeling approaches subjectivity inherent to social systems can be described while maintaining higher objectivity.

Another practical outcome of the tool is that the modeling of customer behavior based on $\mathrm{ABM}$ complements focus group research in addition to performing market surveys. In this case the acceptance of washing machine could be evaluated for Gorenje based on publicly available sources only and without conducting interviews. At this point further empirical data would serve as complementary input to the $\mathrm{ABM}$ to enrich the investigation and validate assumptions.

\section{Conclusions}

This paper provides researchers as well as practitioners with a quantitative analysis tool to study customer behavior in the light of business model changes in CE context. This agentbased model delivers results based on socio-demographic factors of a population (income, age, education and geographic location) as well as behavior curves reflecting the relative importance of the product attributes price, environmental friendliness and service-orientation. The tool serves as decision support and is capable of identifying proper CE marketing and pricing strategies in order to obtain best fit demand behavior.

To accelerate customer acceptance and to affect the transition time from linear to circular systematic marketing strategies are needed which emphasize single CE value propositions, such as service-orientation and environmental friendliness, with different intensities. This highlights the strategic role of social awareness for the CE movement.

As a modeling method agent-based approach seems highly capable to capture underlying behavioral factors and influences to estimate impact of CE business transitions. By filling the gap between diffusion-based penetration of information and resulting social behavior in the form of product-purchase decisions agent-based models provide more objective results when 
describing social systems (in this case customers/users of products and their social network, and the overall behavior resulting from their mutual interactions). This significantly reduces subjectivity when describing effects on technical systems such as manufacturing systems and leads to an improved understanding of complex adaptive systems and usefulness of ABM in industrial dynamics.

Still, the underlying assumption that customers have empathy towards environmental friendly products as well as preference of access over ownership requires strengthening. Future empirical research needs to investigate population specific relevance of the attributes including price, environmental friendliness and service-orientation in order to tap full potential of the tool. The current agent-based model would benefit from more detailed modeling of sub-populations with more specified customer segmentation in different city districts. Finally, this model should be extended and linked to aspects of product design and supply chains management while keeping an optimal profit strategy when changing business models.

Acknowledgements This work has been conducted as part of the ResCoM project that has received funding from the European Union's Seventh Programs for research, technological development and demonstration under Grant agreement No. 603843. The authors are grateful to Gorenje for interesting and fruitful discussions during the course of this work.

Open Access This article is distributed under the terms of the Creative Commons Attribution 4.0 International License (http://creativecommons.org/licenses/by/4.0/), which permits unrestricted use, distribution, and reproduction in any medium, provided you give appropriate credit to the original author(s) and the source, provide a link to the Creative Commons license, and indicate if changes were made.

\section{References}

1. Ellen Macarthur Foundation. (2013). Towards the Circular Economy: Economic and business rationale for an accelerated transition (Online). https://www.ellenmacarthurfoundation.org/assets/downloads/ publications/Ellen-MacArthur-Foundation-Towards-the-Circular-Economy-vol.1.pdf.

2. Lieder, M., \& Rashid, A. (2015). Towards Circular Economy implementation: A comprehensive review in context of manufacturing industry. Journal of Cleaner Production, 115, 36-51.

3. van Dam, K. H., Nikolic, I., \& Lukszo, Zofia. (2013). Agent-based modelling of socio-technical systems (Vol. 9). Yokohama: Springer.

4. Asif, F. M., Bianchi, C., Rashid, A., \& Nicolescu, C. M. (2012). Performance analysis of the closed loop supply chain. Journal of Remanufacturing, 2(1), 4.

5. Rashid, A., Asif, F Ma., Krajnik, P., \& Nicolescu, C. M. (2013). Resource conservative manufacturing: An essential change in business and technology paradigm for sustainable manufacturing. Journal of Cleaner Production, 57, 166-177.

6. Rogers, E. M. (2003). Diffusion of innovations (5th ed.). New York: Free Press.

7. Asif, F. M. A., Lieder, M., \& Rashid, A. (2016). Multi-method simulation based tool to evaluate economic and environmental performance of circular product systems. Journal of Cleaner Production, 139, 12611281.

8. Rand, W., \& Rust, R. T. (2011). Agent-based modeling in marketing: Guidelines for rigor. International Journal of Research in Marketing, 28(3), 181-193.

9. Wolf, I., Schroeder, T., Neumann, J., \& de Haan, G. (2015). Changing minds about electric cars: An empirically grounded agent-based modeling approach. Technological Forecasting and Social Change, 94, 269-285.

10. Mcpherson, M., Smith-Lovin, L., \& Cook, J. (2001). Birds of a feather: Homophily in social networks. Annual Review of Sociology, 27(2001), 415-444.

11. Diao, J., Zhu, K., \& Gao, Y. (2011). Agent-based simulation of durables dynamic pricing. Systems Engineering Procedia, 2, 205-212.

12. Zhang, T., \& Zhang, D. (2007). Agent-based simulation of consumer purchase decision-making and the decoy effect. Journal of Business Research, 60(8), 912-922.

13. Marshall, A. (1920). Principles of economics. An introductory volume (8th ed.). London: Macmillan. 
14. Hajaj, C., Hazon, N., \& Sarne, D. (2017). Enhancing comparison shopping agents through ordering and gradual information disclosure. Autonomous Agents and Multi-Agent Systems, 31(3), 696-714. doi:10. 1007/s10458-016-9342-8.

15. Pasquier, P., \& Chaib-draa, B. (2005). Agent communication pragmatics: The cognitive coherence approach. Cognitive Systems Research, 6, 364-395.

16. Visser, S., Thangarajah, J., Harland, J., \& Dignum, F. (2016). Preference-based reasoning in BDI agent systems. Autonomous Agents and Multi-Agent Systems, 30(2), 291-330.

17. Lang, J., Van Der Torre, L., \& Weydert, E. (2002). Utilitarian desires. Autonomous Agents and Multi-Agent Systems, 5(3), 329-363.

18. Šperka, R., \& SpisŠák, M. (2014). Trading agents' negotiation in business management using demand functions: Simulation experiments with binomial distribution. Procedia Computer Science, 35, 14361444.

19. Kiesling, E., Guenther, M., Stummer, C., \& Wakolbinger, L. M. (2009). An agent-based simulation model for the market diffusion of a second generation biofuel. In Winter Simulation Conference Proceedings, no. Rogers 2003 (pp. 1454-1461).

20. Van Der Veen, R. A. C., Kisjes, K. H., \& Nikolic, I. (2017). Exploring policy impacts for servicising in product-based markets: A generic agent-based model. Journal of Cleaner Production, 145, 1-13.

21. Bass, F. M. (1969). A new product growth for model consumer durables. Management Science, 15(5), 215-227.

22. Stummer, C., Kiesling, E., Günther, M., \& Vetschera, R. (2015). Innovation diffusion of repeat purchase products in a competitive market: An agent-based simulation approach. European Journal of Operational Research, 245(1), 157-167.

23. Anderson, E. W. (1998). Customer satisfaction and word of mouth. Journal of Service Research, 1(1), 5-17.

24. Silvia, C., \& Krause, R. M. (2016). Assessing the impact of policy interventions on the adoption of plug-in electric vehicles: An agent-based model. Energy Policy, 96, 105-118.

25. Jager, W., Janssen, M., \& Bockarjova, M. (2014). Diffusion dynamics of electric cars and adaptive policy: Towards an empirical based simulation. Advances in Social Simulation, 229, 107-118.

26. Rai, V., \& Robinson, S. A. (2015). Agent-based modeling of energy technology adoption: Empirical integration of social, behavioral, economic, and environmental factors. Environmental Modelling and Software, 70, 163-177.

27. Zhang, H., Vorobeychik, Y., Letchford, J., \& Lakkaraju, K. (2016). Data-driven agent-based modeling, with application to rooftop solar adoption. Autonomous Agents and Multi-Agent Systems, 30(6), 10231049.

28. Engel, J. F., Blackwell, R. D., \& Miniard, P. W. (1995). Consumer behavior (Vol. 8th). Philadelphia: The Dryden Press.

29. Grimm, V., Berger, U., DeAngelis, D. L., Polhill, J. G., Giske, J., \& Railsback, S. F. (2010). The ODD protocol: A review and first update. Ecological Modelling, 221(23), 2760-2768.

30. SCB Statistiska centralbyrån - Statistics Sweden. (2014). Income statistics Stockholm (sammanräknad förvärvsinkomst hela året). Statistical database; Household finances. [Online]. http://www.scb.se/ hittastatistik/. Accessed March 21, 2016.

31. City municipality of Stockholm - Stockolm stad. (2014). Age distribution Stockholm 2014 (folkmängd, hela staden per 31 dec 2014). [Online]. http://www.statistikomstockholm.se/index.php/detaljeradstatistik. Accessed March 21, 2016.

32. SCB Statistiska centralbyrån - Statistics Sweden. (2014). Educational levels of the Stockholm population (befolkningens utbildning Stockholm) [Online]. http://www.scb.se/sv_/Hitta-statistik/Statistik-efteramne/Utbildning-och-forskning/Befolkningens-utbildning/Befolkningens-utbildning/\#c_undefined. Accessed March 21, 2016.

33. Sterman, J. D. (2000). Business dynamics: Systems thinking and modeling for a complex world. Boston: McGraw-Hill Companies. 